\title{
Automating Cloning by Natural Transformation
}

Jiang, Xinglin; Palazzotto, Emilia; Wybraniec, Ewa; Munro, Lachlan Jake; Zhang, Haibo; Kell, Douglas; Weber, Tilmann; Lee, Sang Yup

Published in:

A C S Synthetic Biology

Link to article, DOI:

10.1021/acssynbio.0c00240

Publication date:

2020

Document Version

Peer reviewed version

Link back to DTU Orbit

Citation (APA):

Jiang, X., Palazzotto, E., Wybraniec, E., Munro, L. J., Zhang, H., Kell, D., Weber, T., \& Lee, S. Y. (2020). Automating Cloning by Natural Transformation. A C S Synthetic Biology, 9(12), 3228-3235.

https://doi.org/10.1021/acssynbio.0c00240

\section{General rights}

Copyright and moral rights for the publications made accessible in the public portal are retained by the authors and/or other copyright owners and it is a condition of accessing publications that users recognise and abide by the legal requirements associated with these rights.

- Users may download and print one copy of any publication from the public portal for the purpose of private study or research.

- You may not further distribute the material or use it for any profit-making activity or commercial gain

- You may freely distribute the URL identifying the publication in the public portal

If you believe that this document breaches copyright please contact us providing details, and we will remove access to the work immediately and investigate your claim. 


\title{
Automating cloning by natural transformation
}

Xinglin Jiang, Emilia Palazzotto, Ewa Wybraniec, Lachlan Jake Munro, Haibo Zhang, Douglas B. Kell, Tilmann Weber*, and Sang Yup Lee*

\begin{abstract}
:
Affordable and automated cloning platforms are essential to many synthetic biology studies. However, the traditional E. coli-based cloning is a major bottleneck as it requires heat shock or electroporation implemented in the robotic workflows. To overcome this problem, we explored bacterial natural transformation for automatic DNA cloning and refactoring. Recombinant plasmids are efficiently generated from Gibson- or overlap extension PCR (OE-PCR) products by simply adding the DNA into Acinetobacter baylyi ADP1 cultures. No DNA purification, competence induction, or special equipment is required. Up to ten thousand colonies were obtained per microgram DNA while the number of false positive colonies was greatly reduced in comparison to $E$. coli cloning protocols. We cloned and refactored 21 biosynthetic gene clusters (BGCs) of various types, with length from 1.5 to $19 \mathrm{~kb}$, and GC content from $35 \%$ to $72 \%$. One of them, a refactored nucleoside BGC, showed antibacterial activity. Furthermore, the method was easily transferred to a low-cost benchtop robot with consistent cloning efficiency. Thus, this automatic natural transformation (ANT-) cloning provides an easy, robust and affordable platform for high throughput DNA engineering.
\end{abstract}

KEYWORDS: automated cloning, bench-top robot, natural transformation, Acinetobacter baylyi ADP1, biosynthetic gene clusters 
Recently, the amount and quality of bioinformatic data are increasing explosively thanks to the advent of DNA sequencing and genome mining. ${ }^{1}$ High throughput synthetic biology platforms are thus required more than ever to explore them, to discover new knowledge and new bioproducts. However compared to the rapid development of DNA sequencing and synthesis, DNA cloning methodologies have not seen major updates. When DNA cloning was first developed in the 1970s, E. coli was chosen as the cloning host because it is a model organism, shows rapid growth, and most importantly could be transformed with ligation products after calcium ion treatment. ${ }^{2}$ Later, electroporation was adopted for $E$. coli and showed higher efficiency for cloning larger DNA fragments. ${ }^{3}$ The $E$. coli transformation involves heat shock or electric shock of competent cells prepared by multiple rounds of washing. Temperatures need to be precisely controlled throughout the process. DNA substrates for electroporation need to be purified to reduce the ionic strength. Both methods are prone to cell lysis, and the surviving cells need to be recovered in rich medium before being selected on antibiotic agar plates. This complexity makes E. coli based cloning one of the major bottlenecks in high throughput studies. Common laboratory robots handle liquid pipetting very well, i.e. they can efficiently perform bacterial inoculation, enzymatic reaction preparation, PCR preparation, serial dilution, etc. The process of $E$. coli transformation, however, requires expensive infrastructures and is challenging to perform on an affordable robotics setup.

Certain bacteria can actively take up exogenous DNA through a phenomenon called natural transformation. It is a mechanism for getting DNA repair templates from sister cells or acquiring new genetic traits from other species. ${ }^{4}$ DNA molecules are captured by competence pili, and pulled to the cell surface. An ATP-dependent protein complex on the cell membrane digests one of the strands and transports the other into the cytoplasm. The incoming DNA is incorporated into the genome by homologous recombination or digested as a nutrient source. ${ }^{5}$ Natural transformation has previously been used for cloning purpose in Bacillus subtilis. ${ }^{6-7}$ Acinetobacter baylyi ADP1, a soil bacterium from the class Pseudomonadales has one of the highest reported efficiencies of natural transformation. ${ }^{8}$ It grows quickly on simple media with versatile carbon sources, and has plenty of genetic tools available. ${ }^{9}$ Its robust metabolism and the ability to excrete enzymes are also attractive characteristics for biotechnological and environmental applications. ${ }^{10}$ Natural transformation of $A$. baylyi ADP1 does not require induction and the DNA substrate doesn't need to be purified or concentrated. ${ }^{8}$ Taking advantage of this, A. baylyi ADP1 has been used as a model organism to study horizontal gene transfer in situ, ${ }^{11}$ to elucidate dissemination of plant transgenes in soil, ${ }^{12}$ to construct a single-gene knockout library, ${ }^{13}$ to improve protein or biochemical productions by fast metabolic engineering ${ }^{14}$ and multiplex genomic engineering. ${ }^{15}$ In a previous study, we showed that natural transformation was used by Gram-negative bacteria to obtain antibiotic resistance genes or even whole antibiotic BSGs and experimentally reproduced this process with $A$. baylyi ADP1. ${ }^{16}$ In this study, we demonstrated for the first time the high efficiency cloning of DNA targets onto self-replicating plasmids using A. baylyi ADP1. We combined A. baylyi ADP1 natural transformation with robotic automation and thereby provided ANT cloning, a robust, affordable and high throughput cloning platform. 


\section{RESULTS AND DISCUSSION}

\section{Recombinant plasmids are generated from multiple DNA fragments by Acinetobacter natural transformation}

To date, two gram-negative bacteria, A. baylyi ADP1 and Vibrio natriegens, are reported to have the highest transformation efficiencies and are both proposed as alternative model organisms to $E$. coli. ${ }^{8,17} \mathrm{~V}$. natriegens needs chemical induction to become competent, ${ }^{18}$ and in our test showed higher spontaneous resistant mutation on antibiotic agar plates (Supplementary Table 1). Thus in the following experiments we focused on A. baylyi ADP1.

As a proof of concept, we first tested the cloning of the melanin BGC from Streptomyces coelicolor A3(2). This is a type III PKS gene cluster and has been used as a reporter system for gene cluster expression and host metabolic engineering. ${ }^{19,20}$ DNA fragments of $1.5,4$ and $8 \mathrm{~kb}$ covering part of or the whole gene cluster were chosen as the cloning targets (Figure 1a). PCR primers were designed to amplify them and with 30 nt overlap sequences added on $5^{\prime}$ ends for Gibson and OE-PCR assembly. Amplification of the $8 \mathrm{~kb}$ fragment turned out to be difficult (Supplementary Figure 1), due to the high GC content, so it was further divided into two $4 \mathrm{~kb}$ fragments overlapping with each other by $30 \mathrm{bp}$ (Figure 1a).

a

Streptomyces coelicolor A3(2):

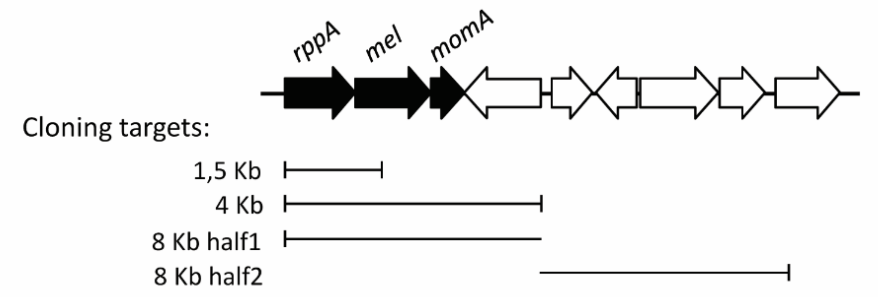

b
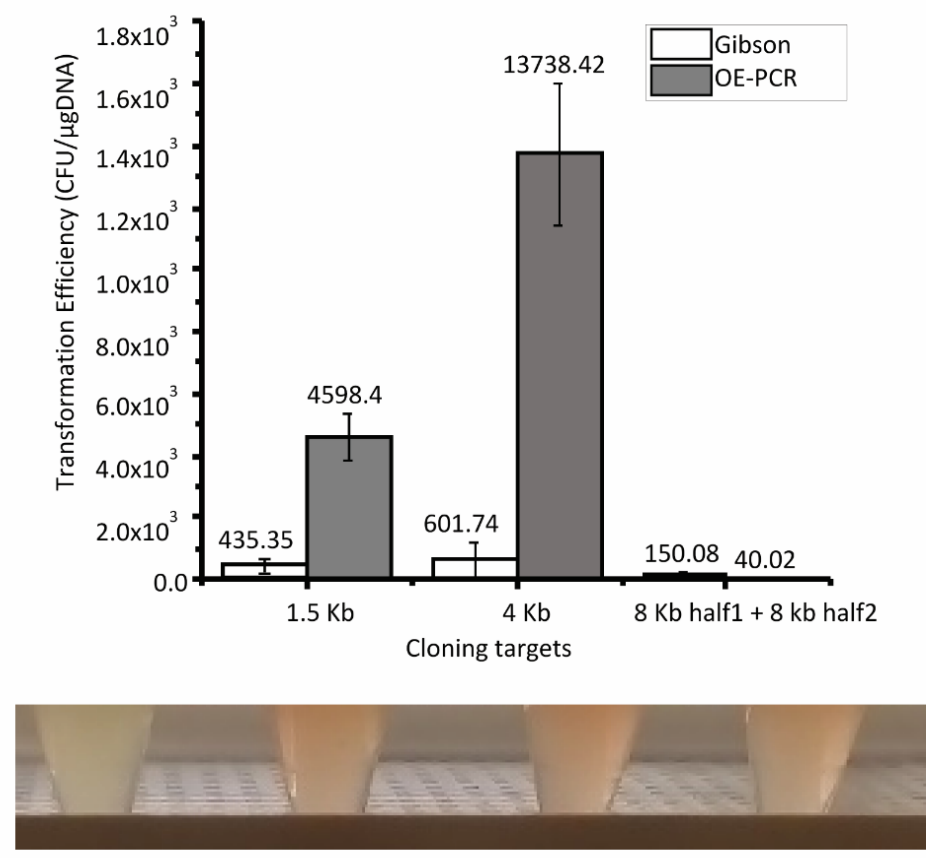

E. coli BL21 (DE3) /pUCP24

E. coli BL21 (DE3)

/pUCP24-8 kb 
Figure 1. Test of natural transformation based DNA cloning. (a) S. coelicolor melanin BGC (black arrows) and the ranges of cloning targets. The 8 kb fragment was too big to be efficiently amplified in a single piece (Supplementary Figure 1), so it was divided into two overlapping fragments 8 kb half1 and $8 \mathrm{~kb}$ half2. The $1.5 \mathrm{~kb}$ and $4 \mathrm{~kb}$ fragments were cloned individually. Fragments $8 \mathrm{~kb}$ half1 and $8 \mathrm{~kb}$ half 2 were cloned together in a single reaction. (b) Cloning efficiency of different targets. The cloning targets were PCR amplified from S. coelicolor gDNA and assembled by Gibson reaction or OEPCR with a plasmid vector backbone amplified from pUCP24. Natural transformation was performed by adding the assembly products directly into $A$. baylyi ADP1 liquid culture, followed by selection on gentamicin agar plate. Error bars indicated the standard deviation of three transformation replicates. (C) Pigment production from the cloned gene cluster. Plasmids containing the $8 \mathrm{~kb}$ fragment were isolated from three individual colonies and expressed in E. coli BL21(DE3) host. Empty plasmid pUCP24 was used as a negative control.

The $1.5 \mathrm{~kb}, 4 \mathrm{~kb}, 8 \mathrm{~kb}$ half1 and $8 \mathrm{~kb}$ half2 fragments were amplified from S. coelicolor genomic DNA. The vector backbone was amplified from plasmid pUCP24. They were subsequently assembled by Gibson or OEPCR, two methods ideal for high throughput cloning as they are simple, independent of restriction enzymes, and sequence-independent. ${ }^{21}$ OE-PCR generates assembly products in multimer form which is a preferred substrate for natural transformation. ${ }^{7,22}$ The Gibson reaction generates both multimer and monomer products. ${ }^{23} \mathrm{Gel}$ electrophoresis results confirmed that assembly products were generated (Supplementary Figure 2). The assembly reactions were then added into $A$. baylyi ADP1 liquid culture, incubated at $30^{\circ} \mathrm{C}$ overnight and then selected on antibiotic agar plate. Up to 13,738 colonies per microgram DNA were obtained with the $4 \mathrm{~kb}$ fragment. OE-PCR products were more efficient than Gibson products for cloning the 1.5 and $4 \mathrm{~kb}$ fragments, but not for the $8 \mathrm{~kb}$ fragment (Figure. $1 \mathrm{~b}$ ). This is probably because, like in standard $P C R$, in OE-PCR the DNA polymerase also cannot efficiently copy long high GC sequences. Colony PCR confirmed that ten out of ten colonies were correct in the $1.5 \mathrm{~kb}$ cloning and $80 \%$ colonies were correct in the $4 \mathrm{~kb}$ and $8 \mathrm{~kb}$ cloning (Supplementary Figure 3). The plasmids were further verified by DNA sequencing and showed pigment production when expressed in E. coli BL21 (DE3) (Figure 1c).

\section{Cloning can be performed in liquid medium or on top of solid medium}

Natural transformation of bacteria has been reported in liquid medium, ${ }^{13}$ on the surface of solid medium, ${ }^{24}$ in biofilm, ${ }^{24}$ in soil, ${ }^{12}$ and on plant tissues. ${ }^{25}$ Here we compared three conditions for the natural transformation based cloning, namely in LB liquid medium in deep well plates with or without shaking, or on top of LB agar. From the same amount of DNA, three protocols generated comparable cloning efficiency (Table 1). Liquid medium with shaking was used in the following experiments as it is easier to perform and also easier to separate single colonies. Without shaking, biofilm formed on the surface of the liquid culture, making it difficult to spread on selection agar plates. 
Table 1. Colony numbers obtained by different transformation protocols.

OE-PCR products from pUCP24 backbone alone (negative control) or from pUCP24 backbone and the 4 kb fragment were used to transform $A$. baylyi ADP1. +/- indicated standard deviation of three transformation replicates.

\begin{tabular}{llll}
\hline $\begin{array}{l}\text { Colony number per micro } \\
\text { gram DNA }\end{array}$ & $\begin{array}{l}\text { Transformation on } \\
\text { top of LB agar }\end{array}$ & $\begin{array}{l}\text { Transformation in } \\
\text { liquid LB }\end{array}$ & $\begin{array}{l}\text { Transformation in liquid LB with } \\
\text { shaking at 220 rpm }\end{array}$ \\
\hline pUCP24 backbone & $20 \pm 20$ & $40 \pm 17$ & $27 \pm 15$ \\
& & & $10133 \pm 1026$ \\
\hline
\end{tabular}

\section{Natural product BGCs were cloned by this new method}

Natural products have contributed to or inspired more than half of the small molecule drugs used in the clinic. ${ }^{26}$ Cloning novel BGCs and expressing them in heterologous hosts is a promising strategy to revive the drug discovery pipeline which has been suffering from high rates of rediscovery of known compounds. ${ }^{27-28}$ Here we used natural transformation on parallel cloning of novel antibiotic BGCs predicted by antiSMASH. ${ }^{29}$ Because antibiotic compounds can be toxic to the cloning and expression hosts, a tight and inducible T7 promoter was used in a new cloning vector pXJ100. One non-typical, one NRPS, two nucleoside, and 17 RIPP BGCs were chosen from Streptomyces, Pseudomonas, Photorhabdus and Xenorhabdus genomes (Supplementary Table 2, 3, and 4). They have a size range from 1 to $19 \mathrm{~kb}$, and a GC range from 35\% to 73\%, cloned as a single fragment or divided into two fragments for refactoring (Supplementary Table 2). The cloning was carried out in 96 deep well plates from Gibson products. Correct plasmids were expressed in $E$. coli BL21(DE3) or Pseudomonas putida KT2440 for product activity screening. Among the 21 BGCs tested, antibacterial activity was detected from gene cluster NN1 cloned from Photorhabdus asymbiotica ATCC43949. It is a nucleoside BGC containing 16 genes as a single operon. The original sequence of it is disrupted by an insertion sequence (IS) in the middle. To restore the functional BGC, the IS was eliminated by a two-fragment cloning (Figure 2a). Its yet to be identified product showed antibacterial activity against Bacillus subtilis (Figure 2b). 
a Photorhabdus asymbiotica ATCC43949

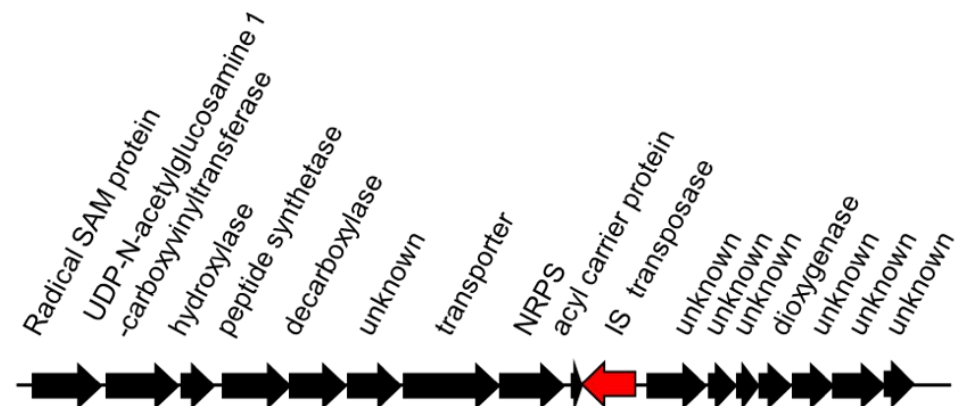

Cloning inserts:

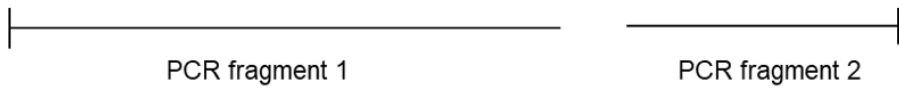

b

E.coli BL21 (DE3) /pXJ100-NN1

E.coli BL21 (DE3) /pXJ100

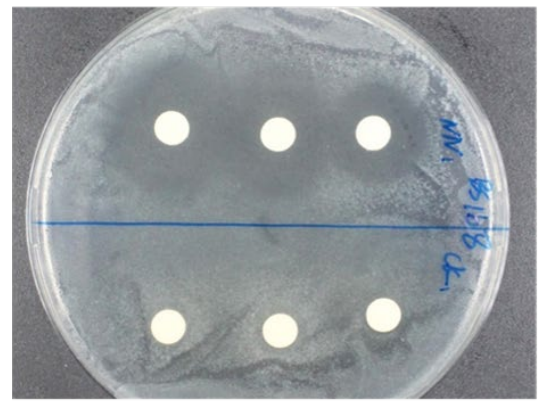

Repeat 1, 2, 3

Figure 2. Cloning and refactoring of gene cluster NN1. (a) The map of gene cluster NN1 from P. asymbiotica ATCC43949. An IS transposon (red arrow) disrupted the gene cluster (black arrows). Two fragments before and after the IS were amplified individually and assembled together onto pXJ100 vector backbone. By this way, the gene cluster was restored. (b) Inhibition zones generated by NN1 gene cluster product. The cloned NN1 gene cluster was expressed in E. coli BL21(DE3) and tested against B. subtilis BS168. Empty plasmid pXJ100 was used as negative control.

\section{Knocking out HsdR restriction does not improve cloning efficiency}

Bacterial restriction-modification (RM) systems are known to be a defense mechanism against foreign DNA. Knocking out RM systems is a general strategy to increase the electrotransformation efficiency of various bacteria. In the case of natural transformation, the role of RM however is more complicated and may vary from bacterium to bacterium. ${ }^{30-31}$ In Pseudomonas stutzeri, deficiency in RM resulted in increased natural transformation efficiency. ${ }^{32}$ As Acinetobacter is closely related to Pseudomonas, we tested if A. baylyi natural transformation can be further improved in a similar way. Genome analysis revealed a type I restriction system, HsdRSM, in A. baylyi. In a previous study HsdRSM was resistant to gene deletion, suggesting it was expressed as a toxin-antitoxin pair. ${ }^{33}$ Hence, we targeted only the restriction enzyme HsdR, while keeping the modification enzyme intact. The inactivation was performed by replacing $68 \mathrm{bp}$ in the middle of $h s d R$ (ACIAD_RS15520) with a chloramphenicol resistance marker, resulting in strain ADP1 hsdR::cat (Figure 3a).

The transformation efficiency of wild-type strain and ADP1 hsdR::cat were investigated using plasmid pucp24 and pXJ100-NN1. The plasmid DNA was used directly or first amplified into multimer by rolling circle amplification (RCA) $\cdot{ }^{34}$ In all cases, the transformation efficiencies of ADP1 hsdR::cat were no higher than the 
wild type strain (Figure $3 \mathrm{~b}$ ). In addition, previous studies showed that A. baylyi ADP1 doesn't apparently discriminate exogenous DNA from different organisms. ${ }^{35}$ DNA from unrelated bacteria, plants, or PCR amplification can efficiently transform A. baylyi ADP1. Therefore, the wild type strain was used in following cloning.

a

Acinetobacterbaylyi ADP1

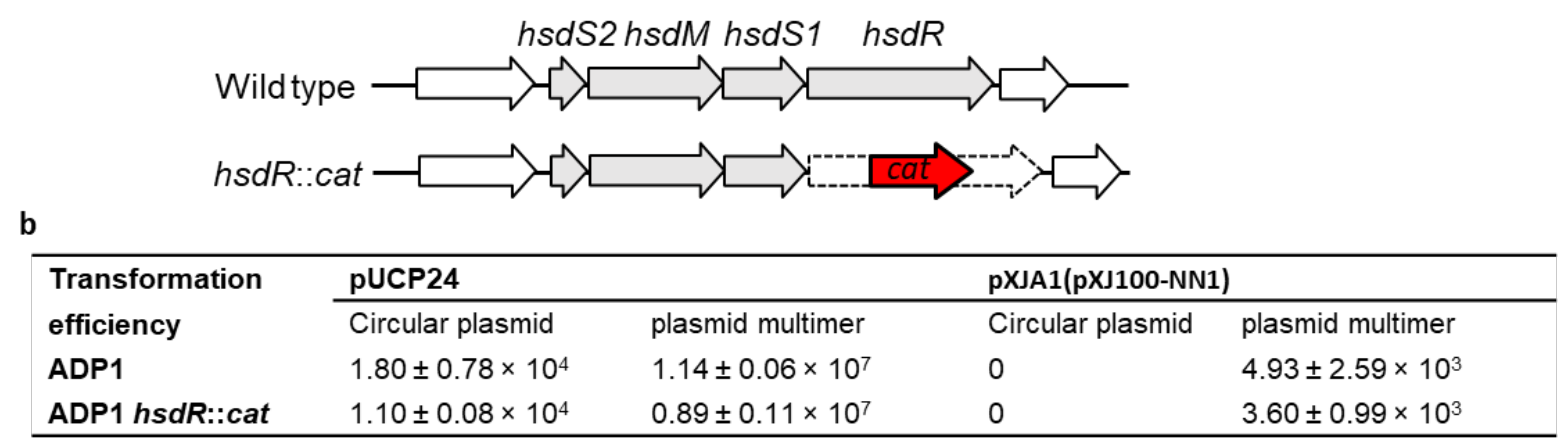

Figure 3. Transformation efficiency of A. baylyi ADP1 WT and ADP1 hsdR::cat. (a) Construction of ADP1 hsdR::cat. Genes of the restriction system are shown as gray arrows. The endonuclease gene $h s d R$ was inactivated by replacing $68 \mathrm{bp}$ in the middle of it with a chloramphenicol resistance marker cat (red arrow). (b) Transformation efficiency with circular plasmids and plasmid multimers. Plasmid pUCP24 and pXJ100-NN1 were used in the test. Circular plasmids were prepared by isolating from E. coli. Plasmid multimers were prepared by rolling circle amplification of the circular plasmids. $+/-$ indicated standard deviation of three transformation replicates.

\section{A. baylyi ADP1 cloning has higher true-positive ratios than E. coli cloning}

E. coli cloning is often hampered by "false positive" colonies caused by uncut circular vector template or selfligation of vector backbone. These empty plasmid molecules are smaller than the desired recombinant plasmids, thus have higher efficiency to be transferred into $E$. coli cells ${ }^{36}$. Consequently, laborious gel purification is required to eliminate those empty plasmid molecules or colony PCR is required to find the correct ones from screening a large number of colonies ${ }^{37}$. For natural transformation, circular monomer plasmids were poorer substrates than linear multimers (Figure. 3b), which is in consistent with previous reports. ${ }^{22,38}$ We reasoned that contamination of the circular empty plasmids in the Gibson and OE-PCR reactions should therefore be discriminated against by natural transformation and thus cause less false positive colonies than in E. coli cloning. To test this, we compared the positive ratio of A. baylyi ADP1 cloning and E. coli cloning from the same OE-PCR product of a GFP cloning (Figure 4). A. baylyi ADP1 cloning showed higher positive ratios than $E$. coli in all three repeats. 


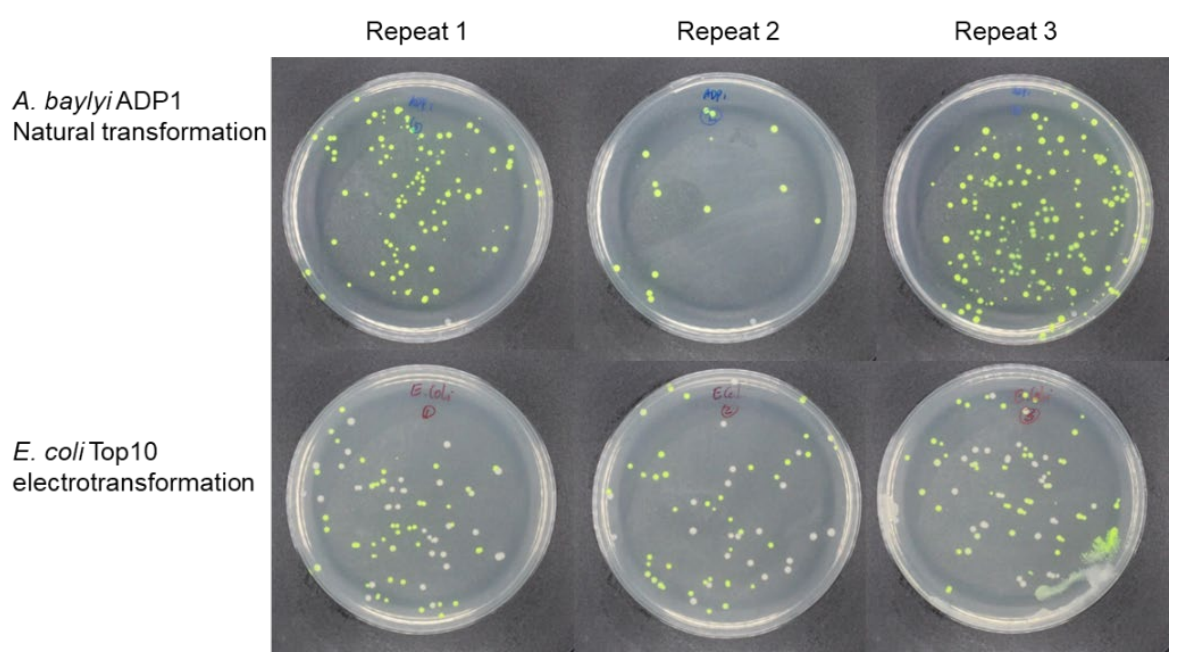

Figure 4. Comparison between A. baylyi ADP1 cloning and E. coli cloning. A DNA fragment containing GFP gene was assembled with a pUCP24 based vector PXJDP by OE-PCR. The product was directly used for A. baylyi ADP1 natural transformation, or purified by ethanol precipitation then used for E. coli electroporation.

\section{A low-cost benchtop robot can reliably perform the natural transformation based cloning}

Recently, low-cost bench top robots became available on the market. The natural transformation based cloning requires only the mixing of DNA and bacterial culture, which is ideal for robotic handling. We therefore developed an automated cloning platform by combining bacterial natural transformation and the Opentrons OT-2 liquid handling robot. Two quality controls were designed for monitoring the cloning efficiency and positive ratio. A GFP fragment was used as the one fragment cloning control. An mScarlet gene fragment and a chloramphenicol resistant gene fragment were used as the two-fragment cloning control. We applied automated cloning to create a series of gene knockout derivatives of the non-typical BGC (Figure 5a). This BGC was chosen because it has an unusual gene composition and its product is yet to be discovered. ${ }^{39}$ Cloning efficiencies by the robot were similar to that achieved in manual operation and above $90 \%$ of the control colonies were green or red (Figure $5 \mathrm{~b}$ and c). Three colonies for each of the BGC derivatives were picked and made into glycerol stocks, of which two or three contain correctly constructed plasmids (Figure 5b). 
a

Pseudomonas putida W15Oct28

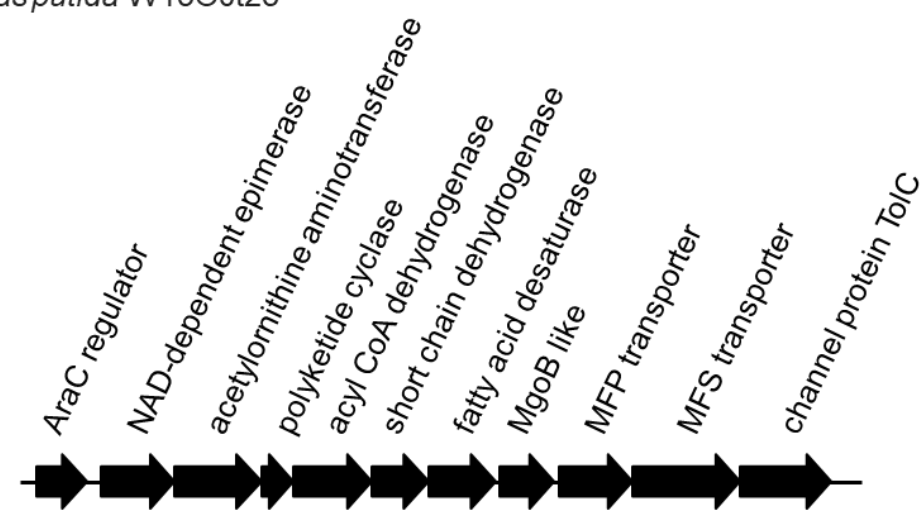

pXJ112delta2-5

pXJ112delta8

pXJ112delta9-11

pXJ112delta2-5,8-11

b

\begin{tabular}{lll}
\hline Cloning & $\begin{array}{l}\text { Colony number per } \\
\text { transformation }\end{array}$ & Positive ratio \\
\hline One fragment cloning control & 8720 & $91 \%$ \\
Two-fragment cloning control & 2680 & $90 \%$ \\
pXJ112delta2-5 & 4510 & $3 / 3$ \\
pXJ112delta8 & 740 & $2 / 3$ \\
pXJ112delta9-11 & 5790 & $3 / 3$ \\
pXJ112delta2-5,8-11 & 7040 & $3 / 3$ \\
\hline
\end{tabular}

c

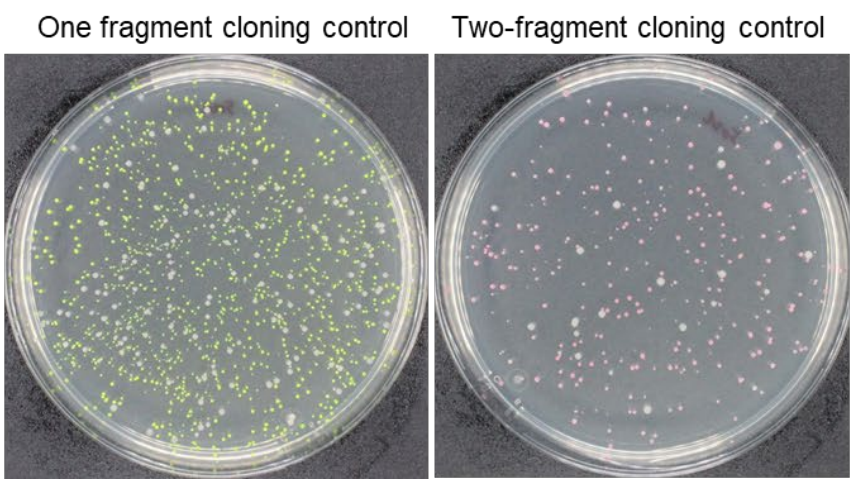

Figure 5. Cloning on Opentrons OT-2 robot. (a) Map of the non-typical BGC and cloning inserts. The BGC was discovered from Pseudomonas putida W15Oct28 and has an unusual gene composition. Four derivatives were designed with certain genes removed by choosing different cloning inserts. (b) Cloning efficiency. The one fragment cloning control uses a GFP gene fragment as the insert. The two-fragment cloning control uses an mScarlet gene fragment and a chloramphenicol resistant gene fragment as the inserts. Positive ratios were calculated by counting the green or red colonies or by colony PCR. (c) Photos of the two cloning controls. 


\section{CONCLUSION}

High-throughput DNA cloning is important for many studies. So far, automation of cloning protocols was, however, limited to only well-funded companies or specialized institutes. In this study we have developed a natural transformation based cloning method that requires only the adding of DNA substrates into liquid bacterial cultures. High efficiency and positive ratios are achieved for a wide range of DNA sizes, GC contents and BGC types. It can be easily performed on low-cost lab robots and no expensive equipment or additional consumable is required. Thus, it provides a powerful platform for high throughput synthetic biology studies.

\section{MATERIALS AND METHODS}

\section{Enzymes and kits}

Phusion Hot Start II DNA polymerase or Q5 Hot Start DNA polymerase from Thermo Fisher Scientific (USA) were used for PCR amplification and OE-PCR assembly. OneTaq Quick-Load 2X Master Mix was used for colony PCR. Betaine from Sigma-Aldrich (Germany) was used as PCR enhancer for high GC DNA. ${ }^{40-41}$ Primer oligos were synthesized by IDT in tube or well plate format (Integrated DNA Technology). Primer sequences are summarized in Supplementary Table S5. NucleoSpin plasmid kit from MACHEREY-NAGEL was used for Acinetobacter plasmid isolation. Illustra TempliPhi 100 Amplification Kit was used for rolling circle amplification of plasmids.

\section{DNA assembly}

The Gibson Assembly Master Mix from New England BioLabs(USA) was incubated with DNA substrates for 1 hour according to the supplier protocol. OE-PCR assembly was performed by the method from You et al. ${ }^{7}$ In brief, DNA fragments were mixed into standard PCR reaction but without additional oligo primers. The DNA fragments prime each other by their overlaps and get assembled into long multimers. The assembly products were directly used for natural transformation of $A$. baylyi ADP1 or purified by ethanol precipitation and then used for electrotransformation of E. coli Top10.

\section{Construction of cloning vector $\mathrm{pXJ100}$}

Three fragments were amplified from pUCP24 by primer pairs xj202 + xj203, xj206 + xj207 and xj208 + xj209. A fragment containing the T7 promoter, multi cloning sites and T7 terminator was amplified from $\mathrm{pET} 28 \mathrm{a}$ by xj204 + xj205. The four fragments were assembled into pXJ100 by Gibson reaction.

\section{Construction of $A$. baylyi ADP1 hsdR::cat}

Two homologous arms were amplified from A. baylyi genomic DNA with primer xj241+xj242 and xj245+xj246. The cat selective marker was amplified from pACYduetl with primer xj243+ xj244. A plasmid backbone was amplified from pUC18 with primer xj247+ xj248. The fragments were assembled by Gibson reaction, transferred into $E$. coli by electroporation and selected on plates with $\mathrm{Cm}$. The resulting plasmid was used to do gene knockout in A. baylyi ADP1 by natural transformation and selection on plate with $\mathrm{Cm}$. Gene replacement was confirmed by colony PCR using primer xj241.1 + xj246.1. 


\section{Natural transformation}

Natural transformation in liquid medium is carried out in 96-deep-well plates or $15 \mathrm{ml}$ Eppendorf tubles. 50 $\mu$ l overnight LB culture was diluted with $0.45 \mathrm{ml}$ fresh LB, added with DNA samples and incubated at $30^{\circ} \mathrm{C}$ overnight with $220 \mathrm{rpm}$ shaking. Natural transformation on top of solid medium is carried out on LB agar plates. $50 \mu$ l overnight LB culture was mixed with DNA samples, dropped on top of LB agar and incubated at $30^{\circ} \mathrm{C}$ overnight. Cells were collected with a plastic loop, suspended in liquid LB then spread on selection agar.

\section{BGC heterologous expression and antibiotic activity screening}

Plasmids were transferred into E. coli BL21(DE3) by heat shock in a 96 well PCR plate or transferred into $P$. putida KT2440 by electroporation. Three random colonies from each plasmid were tested. Cells from $10 \mathrm{ml}$ fresh overnight culture were washed with fresh LB without antibiotic for three times, suspended in $10 \mathrm{ml}$ fresh LB with $0.5 \mathrm{mM}$ IPTG and incubated at $30^{\circ} \mathrm{C}$ with $220 \mathrm{rpm}$ shaking for 24 hours. $100 \mu \mathrm{l}$ of supernatant was dried on a paper dish. Testing plates were prepared by spreading $200 \mu \mathrm{l}$ B. subtilis BS168 culture of 0.2 $\mathrm{OD}_{600}$. The paper dishes were laid onto the testing plates and incubated at $30^{\circ} \mathrm{C}$ overnight. Antibiotic activity was indicated by the formation of inhibition zones.

\section{Automation of Natural Transformation}

Robotic cloning was performed using the Opentrons OT-2 liquid handling robot (opentrons.com). The OT-2 was fitted with two pipettes, a $10 \mu \mathrm{L}$ multichannel pipette and a $300 \mu \mathrm{L}$ single channel pipette. Natural transformation was performed by transferring $5 \mu \mathrm{L}$ DNA samples from a 96-well PCR plate to a 96-deep-well plate prefilled with $450 \mu \mathrm{L}$ A. baylyi ADP1 culture per well (detailed robotic operation can be found in Supplementary Method 1).

\section{AUTHOR INFORMATION}

\section{Corresponding Authors}

Tilmann Weber - The Novo Nordisk Foundation Center for Biosustainability, Technical University of Denmark, 2800 Kgs. Lyngby, Denmark; orcid.org/ 0000-0002-8260-5120; Email: tiwe@biosustain.dtu.dk

Sang Yup Lee - Metabolic and Biomolecular Engineering National Research Laboratory, Department of Chemical and Biomolecular Engineering (BK21 Plus Program), Center for Systems and Synthetic Biotechnology, Institute for the BioCentury, Korea Advanced Institute of Science and Technology (KAIST), Daejeon 34141, Republic of Korea; orcid.org/ 0000-0003-0599-3091; Email: leesy@kaist.ac.kr

\section{Authors}

Xinglin Jiang - The Novo Nordisk Foundation Center for Biosustainability, Technical University of Denmark, 2800 Kgs. Lyngby, Denmark; 
Emilia Palazzotto - The Novo Nordisk Foundation Center for Biosustainability, Technical University of Denmark, 2800 Kgs. Lyngby, Denmark;

Ewa Wybraniec - Technical University of Denmark, 2800 Kgs. Lyngby, Denmark;

Lachlan Jake Munro - The Novo Nordisk Foundation Center for Biosustainability, Technical University of Denmark, 2800 Kgs. Lyngby, Denmark;

Haibo Zhang - Qingdao Institute of Bioenergy and Bioprocess Technology, Chinese Academy of Sciences, Qingdao 266101, P. R. China

Douglas B. Kell - The Novo Nordisk Foundation Center for Biosustainability, Technical University of Denmark, 2800 Kgs. Lyngby, Denmark;

\section{Author Contributions}

X.J. and E.W. set up and optimized the cloning protocol. X.J., E.P. and H.Z performed the BGC cloning, heterologous expression and product activity test. L.J.M. programmed and optimized the opentrons ot-2 robot. X.J., T.W., L.J.M. and D.K. analysed data and drafted the manuscript. T.W. and S.Y.L. supervised the study.

\section{Conflict of Interest}

DTU has filed a patent application EP19166182.6 on the ANT cloning method with XJ, TW and SYL as inventors.

\section{ACKNOWLEDGEMENTS}

We thank Prof. Pierre Cornelis and Dr. Lumeng Ye from Vrije Universiteit Brussel for offer the strain Pseudomonas putida W150ct28. We thank Dr. Douglas McCloskey, Dr. Simo Abdessamad Baallal Jacobsen and Dr. Jerome Maury for their help with robot testing.

This work was funded by grants of the Novo Nordisk Foundation [NNF10CC1016517 to SYL, NNF160C0021746 to TW].

\section{REFERENCES}

1. Ziemert, N.; Alanjary, M.; Weber, T., The evolution of genome mining in microbes - a review. Nat. Prod. Rep. 2016, 33 (8), 988-1005.

2. Cohen, S. N., DNA cloning: A personal view after 40 years. Proc. Natl. Acad. Sci. U. S. A. 2013, 110 (39), 1552115529.

3. Dower, W. J.; Miller, J. F.; Ragsdale, C. W., High efficiency transformation of E.coli by high voltage electroporation. Nucleic Acids Res. 1988, 16 (13), 6127-6145.

4. Johnston, C.; Martin, B.; Fichant, G.; Polard, P.; Claverys, J.-P., Bacterial transformation: distribution, shared mechanisms and divergent control. Nat. Rev. Micro. 2014, 12 (3), 181-196.

5. Ellison, C. K.; Dalia, T. N.; Vidal Ceballos, A.; Wang, J. C.-Y.; Biais, N.; Brun, Y. V.; Dalia, A. B., Retraction of DNAbound type IV competence pili initiates DNA uptake during natural transformation in Vibrio cholerae. Nature Microbiology 2018. 
6. Itaya, M.; Fujita, K.; Kuroki, A.; Tsuge, K., Bottom-up genome assembly using the Bacillus subtilis genome vector. Nat. Methods 2007, 5, 41.

7. You, C.; Zhang, X.-Z.; Zhang, Y.-H. P., Simple Cloning via Direct Transformation of PCR Product (DNA Multimer) to Escherichia coli and Bacillus subtilis. Appl. Environ. Microbiol. 2012, 78 (5), 1593-1595.

8. Elliott, K. T.; Neidle, E. L., Acinetobacter baylyi ADP1: Transforming the choice of model organism. IUBMB Life 2011, 63 (12), 1075-1080.

9. Biggs, B. W.; Bedore, S. R.; Arvay, E.; Huang, S.; Subramanian, H.; Mclntyre, E. A.; Duscent-Maitland, C. V.; Neidle, E. L.; Tyo, K. E. J., Development of a genetic toolset for the highly engineerable and metabolically versatile Acinetobacter baylyi ADP1. bioRxiv 2019, 696302.

10. Parche, S.; Geissdörfer, W.; Hillen, W., Identification and characterization of xcpR encoding a subunit of the general secretory pathway necessary for dodecane degradation in Acinetobacter calcoaceticus ADP1. J. Bacteriol. 1997, 179 (14), 4631-4634.

11. Santala, V.; Karp, M.; Santala, S., Bioluminescence based system for rapid detection of natural transformation. FEMS Microbiol. Lett. 2016.

12. Pontiroli, A.; Ceccherini, M.-T.; Poté, J.; Wildi, W.; Kay, E.; Nannipieri, P.; Vogel, T. M.; Simonet, P.; Monier, J.M., Long-term persistence and bacterial transformation potential of transplastomic plant DNA in soil. Res. Microbiol. 2010, $161(5), 326-334$.

13. de Berardinis, V.; Vallenet, D.; Castelli, V.; Besnard, M.; Pinet, A.; Cruaud, C.; Samair, S.; Lechaplais, C.; Gyapay, G.; Richez, C.; Durot, M.; Kreimeyer, A.; Le Fèvre, F.; Schächter, V.; Pezo, V.; Döring, V.; Scarpelli, C.; Médigue, C.; Cohen, G. N.; Marlière, P.; Salanoubat, M.; Weissenbach, J., A complete collection of single-gene deletion mutants of Acinetobacter baylyi ADP1. Mol. Syst. Biol. 2008, 4 (1), n/a-n/a.

14. Santala, S.; Efimova, E.; Koskinen, P.; Karp, M. T.; Santala, V., Rewiring the Wax Ester Production Pathway of Acinetobacter baylyi ADP1. ACS Synthetic Biology 2014, 3 (3), 145-151.

15. Dalia, T. N.; Yoon, S. H.; Galli, E.; Barre, F.-X.; Waters, C. M.; Dalia, A. B., Enhancing multiplex genome editing by natural transformation (MuGENT) via inactivation of ssDNA exonucleases. Nucleic Acids Res. 2017, 45 (12), $7527-$ 7537.

16. Jiang, X.; Ellabaan, M. M. H.; Charusanti, P.; Munck, C.; Blin, K.; Tong, Y.; Weber, T.; Sommer, M. O. A.; Lee, S. Y., Dissemination of antibiotic resistance genes from antibiotic producers to pathogens. Nature Communications 2017, 8, 15784.

17. Weinstock, M. T.; Hesek, E. D.; Wilson, C. M.; Gibson, D. G., Vibrio natriegens as a fast-growing host for molecular biology. Nat Meth 2016, 13 (10), 849-851.

18. Dalia, T. N.; Hayes, C. A.; Stolyar, S.; Marx, C. J.; McKinlay, J. B.; Dalia, A. B., Multiplex Genome Editing by Natural Transformation (MuGENT) for Synthetic Biology in Vibrio natriegens. ACS Synthetic Biology 2017.

19. Magdevska, V.; Gaber, R.; Goranovič, D.; Kuščer, E.; Boakes, S.; Durán Alonso, M. B.; Santamaría, R. I.; Raspor, P.; Leadlay, P. F.; Fujs, Š.; Petković, H., Robust reporter system based on chalcone synthase rppA gene from Saccharopolyspora erythraea. J. Microbiol. Methods 2010, 83 (2), 111-119.

20. Yang, D.; Kim, W. J.; Yoo, S. M.; Choi, J. H.; Ha, S. H.; Lee, M. H.; Lee, S. Y., Repurposing type III polyketide synthase as a malonyl-CoA biosensor for metabolic engineering in bacteria. Proc. Natl. Acad. Sci. U. S. A. 2018, 115 (40), 9835-9844.

21. Chao, R.; Yuan, Y.; Zhao, H., Recent advances in DNA assembly technologies. FEMS Yeast Res. 2015,15 (1), 1-9.

22. Kidane, D.; Carrasco, B.; Manfredi, C.; Rothmaier, K.; Ayora, S.; Tadesse, S.; Alonso, J. C.; Graumann, P. L., Evidence for Different Pathways during Horizontal Gene Transfer in Competent Bacillus subtilis Cells. PLoS Genet. 2009, 5 (9), e1000630.

23. Guo, Y.-Y.; Shi, Z.-Y.; Fu, X.-Z.; Chen, J.-C.; Wu, Q.; Chen, G.-Q., A strategy for enhanced circular DNA construction efficiency based on DNA cyclization after microbial transformation. Microbial Cell Factories 2015, 14 (1), 18.

24. Merod, R. T.; Wuertz, S., Extracellular Polymeric Substance Architecture Influences Natural Genetic Transformation of Acinetobacter baylyi in Biofilms. Appl. Environ. Microbiol. 2014, 80 (24), 7752-7757.

25. Rizzi, A.; Pontiroli, A.; Brusetti, L.; Borin, S.; Sorlini, C.; Abruzzese, A.; Sacchi, G. A.; Vogel, T. M.; Simonet, P.; Bazzicalupo, M.; Nielsen, K. M.; Monier, J.-M.; Daffonchio, D., Strategy for In Situ Detection of Natural TransformationBased Horizontal Gene Transfer Events. Appl. Environ. Microbiol. 2008, 74 (4), 1250-1254.

26. Newman, D. J.; Cragg, G. M., Natural Products as Sources of New Drugs from 1981 to 2014. J. Nat. Prod. 2016, $79(3), 629-61$.

27. Kalkreuter, E.; Pan, G.; Cepeda, A. J.; Shen, B., Targeting Bacterial Genomes for Natural Product Discovery. Trends Pharmacol. Sci. 2019.

28. Abbasi, M. N.; Fu, J.; Bian, X.; Wang, H.; Zhang, Y.; Li, A., Recombineering for Genetic Engineering of Natural Product Biosynthetic Pathways. Trends Biotechnol. 2020.

29. Blin, K.; Shaw, S.; Steinke, K.; Villebro, R.; Ziemert, N.; Lee, S. Y.; Medema, M. H.; Weber, T., antiSMASH 5.0: updates to the secondary metabolite genome mining pipeline. Nucleic Acids Res. 2019, 47 (W1), W81-W87. 
30. Thomas, C. M.; Nielsen, K. M., Mechanisms of, and Barriers to, Horizontal Gene Transfer between Bacteria. Nature Reviews Microbiology 2005, 3 (9), 711-721.

31. Johnston, C.; Polard, P.; Claverys, J.-P., The Dpnl/Dpnll pneumococcal system, defense against foreign attack without compromising genetic exchange. Mobile genetic elements 2013, 3 (4), e25582.

32. Berndt, C.; Meier, P.; Wackernagel, W., DNA restriction is a barrier to natural transformation in Pseudomonas stutzeri JM300. Microbiology 2003, 149 (4), 895-901.

33. Lannan, R. Effect of endogenous nucleases on natural transformation of Actinetobacter baylyi ADP1. Honors Theses, The University of Texas at Austin, Austin United States, 2014.

34. Dean, F. B.; Nelson, J. R.; Giesler, T. L.; Lasken, R. S., Rapid Amplification of Plasmid and Phage DNA Using Phi29 DNA Polymerase and Multiply-Primed Rolling Circle Amplification. Genome Res. 2001, 11 (6), 1095-1099.

35. Lorenz, M. G.; Reipschlager, K.; Wackernagel, W., Plasmid transformation of naturally competent Acinetobacter calcoaceticus in non-sterile soil extract and groundwater. Arch. Microbiol. 1992, 157 (4), 355-60.

36. Chan, V.; Dreolini, L. F.; Flintoff, K. A.; Lloyd, S. J.; Mattenley, A. A., The effect of increasing plasmid size on transformation efficiency in Escherichia coli. Journal of Experimental Microbiology and Immunology 2002, 2, $207-223$.

37. Padmanabhan, S.; Banerjee, S.; Mandi, N., Screening of Bacterial recombinants: strategies and preventing false positive. Molecular Cloning-Selected Applications in Medicine and Biology 2011, p1-19.

38. Frischer, M. E.; Thurmond, J.; Paul, J. H., Natural plasmid transformation in a high-frequency-of-transformation marine Vibrio strain. Appl. Environ. Microbiol. 1990, 56 (11), 3439-3444.

39. Ye, L.; Hildebrand, F.; Dingemans, J.; Ballet, S.; Laus, G.; Matthijs, S.; Berendsen, R.; Cornelis, P., Draft Genome Sequence Analysis of a Pseudomonas putida W15Oct28 Strain with Antagonistic Activity to Gram-Positive and Pseudomonas sp. Pathogens. PLoS One 2014, 9 (11), e110038.

40. Kushnir, S.; Sundermann, U.; Yahiaoui, S.; Brockmeyer, A.; Janning, P.; Schulz, F., long pcr --Minimally Invasive Mutagenesis Gives Rise to a Biosynthetic Polyketide Library. Angewandte Chemie International Edition 2012, 51 (42), 10664-10669.

41. Sundermann, U.; Bravo-Rodriguez, K.; Klopries, S.; Kushnir, S.; Gomez, H.; Sanchez-Garcia, E.; Schulz, F., Enzyme-Directed Mutasynthesis: A Combined Experimental and Theoretical Approach to Substrate Recognition of a Polyketide Synthase. ACS Chem. Biol. 2013, 8 (2), 443-450.

\section{For Table of Contents Only:}

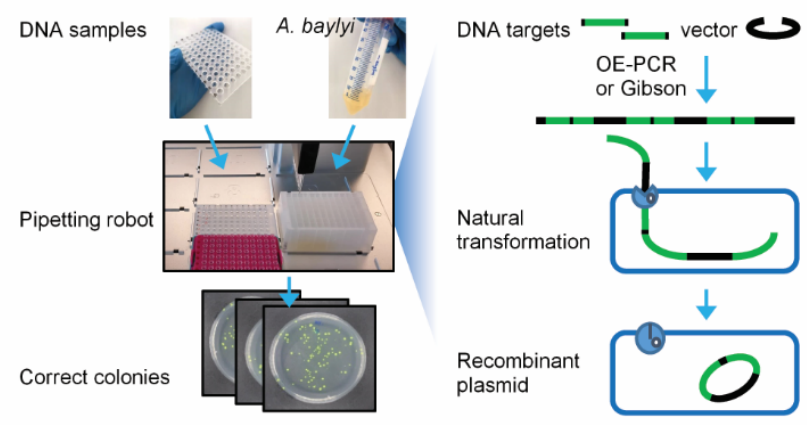

